\title{
OBNOVA IDEJE TREĆEG RIMA
}

\author{
Slavoljub S. Lekić* \\ Univerzitet u Beogradu, Poljoprivredni fakultet
}

Stara ideja Moskva - Treći Rim poslednjih godina prisutna je u jav-

Snom diskursu. Snažan podsticaj njenoj obnovi dao je tomos Sinoda Vaseljenske patrijaršije o autokefalnosti ukrajinske crkve ali i razvoj prilika u Evropi. Pre svega migrantska kriza, politička, kulturna i etnička razgradnja evropskih društava ali i izlazak Velike Britanije iz EU. Projekat Trećeg Rima dnevna zbivanja pretaču u skicu savremenog istočnog carstva oslonjenog na tradiciju ruske i sovjetske imperije. Ovaj geopolitički nacrt, pored drugih koje razmatraju Kremlj, atlantske države, Kina i regionalne sile, opredeljuje budućnost zemalja sanitarnog kordona (od Baltika do Jadrana), a posebno razvoj vojno-političke situacije na Balkanu, području velike geopolitičke napetosti i neizvesnosti.

Ključne reči: Srbija, Rusija, EU, istočna Evropa, sanitarni kordon, Balkan

Uvod

Nakon jednostranog istupanja Britanije i SAD iz sporazuma na Jalti (1945), rušenjem berlinskog zida 1990, svet je ušao u stanje neravnoteže i nepredvidivosti. Sovjetski Savez izgubio je svaki smisao - izgradnja i širenje komunizma bila je nemoguća (nuklearni rat) a socijalizam na prostoru Rusije u vreme Gorbačova već je bio dostigao ciljeve. Ni uspostavljanje Ruskog carstva više nije bila moguće jer bi formacija zasnovana isključivo na ruskoj ideji ostala bez Kavkaza i oblasti u kojima su Rusi manjina. Svaka prinuda nesaglasnih naroda značila bi beskrajni i iscrpljujući rat pogubniji od svih evropskih nasrtaja na Rusiju.

Kremlj nije uspeo da se približi evropskom svetu. Neuspeh ruske elite da se utopi u evropsku, kao i uzaludni pokušaji evropskih naroda da zagospodare ruskim prostranstvima kulminirao je razaranjem društava bivših članica VU poslednje decenije XX stoleća i simboličnim bombardovanjem Beograda i Srbije 1999. Dakle, nove prilike tražile su nove obrasce unutrašnje organizacije i širenja ruskog uticaja na ostatak sveta uz obezbeđenje kontinuiteta sa Sovjetskim Savezom, pre svega na polju vojne industrije, ratovanja i upravljanja velikim prostorom. Privremeno, da bi zamenila dotadašnji ekonomski model, Rusija se iz nužde smestila u zonu dolara.

\section{Novi scenariji Kremlja}

Nakon dubokih preispitivanja i suočavanja s novom stvarnošću, Kremlj je na minhenskoj konferenciji (2007) najavio da odustaje od konvergencije sa evropskim svetom i tu odluku zapečatio slanjem vojske u Abhaziju i Južnu Osetiju (2008). Posle prisajedi- 
njenja Krima (2014), pojavljuju se obrisi novog Projekta Rusija, koji Kremlj iscrtava velikom vojnom i diplomatskom operacijom na Bliskom istoku i u Sredozemlju započetom 2015. Napokon, Kremlj iznosi zahtev da dobije mesto za pregovaračkim stolom koje su imali Romanovi (govor V. Putina 1.3.18). ${ }^{1}$ Atlantski svet odgovara širenjem nezapamćene rusofobije.

Danas Kremlj oprezno ide nepoznatim putem i aktivno pomaže rušenje starog poretka i udara temelje svoje univerzalističke imperije. Zato podržava američke konzervativne kapitaliste predvođene Donaldom Trampom. Kako vreme prolazi Moskva je sve zainteresovanija za osnivanje mnoštva novih instituta međunarodnog karaktera: novog vojnog saveza šireg od Varšavskog pakta, saveta uzajamne ekonomske pomoći, međunarodnog tribunala za ratne zločine i dr. Oni će zameniti klasične evroatlantske institucije u kojima će Kremlj imati vodeću ulogu. Uoči formalizacije novog poretka (podele sfera uticaja), u Rusiji, Kini i Turskoj koncentrisana je vladarska moć u rukama jednog čoveka, dok u evropskim političkim krugovima vlada metež.

Ako se uspostavi poredak u kome će biti više panregiona (centara) udaljenih geografski, ideološki, duhovno (SAD-Rusija-Kina-EU-JAR?-Brazil?), svet bi mogao dostići stabilnost i upravljivost. U XX stoleću dok su tri sile SAD, Velika Britanija i SSSR bile svetski hegemoni, dve su bile ekonomski, vojno i ideološki toliko bliske da je došlo do njihovog objedinjavanja i dotadašnja ravnoteža je narušena.

Ruski vođi su pred teškim i izazovnim zadatkom - uspostavljanjem imperijalnog okvira kojim bi prevazišli sve zaplete i neuspehe revolucionarnog modela u XX stoleću (SSSR) i modela Ruske imperije (Romanovi). Dakle, Kremlj svim snagama traga za novim organizacionim oblicima vojske, privrede (tehnologije) i duhovnosti (ideologije) koji će u narednih 75-100 godina obezbediti postojan razvoj i oporavak Rusije. Da su procesi započeli govore i koraci u prethodnih četvrt stoleća: 1) okretanje Moskve saradnji s Kinom, Korejom, Vijetnamom, Indijom, Japanom (istočni vektor delovanja), 2) prisustvo na Južnom polu i čvrsto zaposedanje Severnog pola (severni vektor), 3) obnova kosmičkih istraživanja i proboji u oblasti vojnih tehnologija, čovekovog života i ljudskog društva (ruski kosmizam); 4) kritička razmišljanja o sovjetskom nasleđu; 5) obnavljanje interesa za Balkan i istočnu Evropu (evropski vektor) i 6) masovni ulazak ruskih trupa na prostor između Jerusalima i Konstantinopolja 2015. (južni vektor).

Da bi pokrenuo izgradnju novog carstva i međunarodnih struktura, Kremlj će morati da sačuva celovitost teritorije Ruske federacije i odupre se završnoj fazi njenog opkoljavanja i obuzdavanja. ${ }^{2}$ Višesmerno kretanje Moskva će usaglašavati s razvojem prilika. Sada su najaktuelnija dejstva na Bliskom istoku, Evropi. Čini se da je danas od izuzetnog značaja za čitavu Evropu staro eshatološko učenje Moskva - Treći Rim, utemeljeno na poslanici ruskog monaha Filoteja (XVI stoleće).

\footnotetext{
* Prof. dr Slavoljub S. Lekić, urednik Foruma Poljoprivrednog fakulteta Univerziteta u Beogradu.

${ }^{1}$ Obraćanje predsednika Rusije V. Putina federalnoj skupštini 1.3.2018. Videti na: https://rs.sputniknews.com/rusija/201803011114740983-Rusija-Vladimir-Putin-obracanje-skupstina-/

${ }^{2}$ Politiku obuzdavanja i opkoljavanja Rusije simbolično je najavio tzv. dugi telegram Džordža Kenana. Videti: George Kennan to George Marshall ["Long Telegram"], February 22, 1946. Harry S. Truman Administration File https://www.trumanlibrary.org/whistlestop/study_collections/coldwar/documents/pdf/6-6.pdf
} 


\section{Treći Rim i Treća internacionala}

Vaseljenska patrijaršija sa sedištem u Konstantinopolju, politički vezana za Vašington i London, novčano zavisna od priloga koje prikuplja širom sveta, pre svega u Americi, upustila se u dodelu autokefalije raskolničkim grupacijama u Ukrajini. Tomos patrijarha Vartolomeja, naišao je na protivljenje pravoslavnih crkava i negativno će uticati na sve pravoslavne zajednice. Carigrad čeka gubitak ugleda. I kako biva u istoriji, odluka kojom se hoće jedno često donosi nešto drugo. ${ }^{3}$ Neočekivano priznanje ukrajinske autokefalije oživelo je i zamah dalo učenju Moskva - Treći Rim. Ali ukrajinski predsednik Porošenko misli da je odluka patrijarha Vartolomeja dalekosežna i da označava pad Trećeg Rima. ${ }^{4}$ Izgleda da je političkom vrhu Ukrajine važnije da prekine veze sa Rusijom nego obim crkvene autokefalnosti i potpuna podređenost nove crkve Konstantinopolju. ${ }^{5}$ Svesni da odluka o autokefaliji može dovesti do ukidanja poslednjeg ostatka Vizantije, helenofoni brižno prate oštru raspravu i pitaju se da li je autokefalija toliko potrebna? ${ }^{6} \mathrm{U}$ isto vreme smatraju da Rusi nemaju razloga da budu Treći Rim u duhu ovog vremena već prva i sveta Moskva u duhovnom smislu. ${ }^{7}$

Mada ograničeno na uske crkvene krugove učenje Moskva - Treći Rim dalo je, posle uzdizanja ruske Mitropolije u rang Patrijaršije (1589), podlogu premeštanju središta pravoslavlja iz Konstantinopolja u Moskvu. Pred ruskim monaštvom i sveštenstvom našlo se pitanje: zašto sedište pravoslavlja iz Carigrada, nakon što su ga zauzeli inoverci, ne bi moglo da bude preneto u Moskvu? Filotejevo razmišljanje o Trećem Rimu ima metaistorijski značaj i u času nastanka nije uticalo na spoljnu politiku Rusije. Postalo je idejna potka moskovskog carstva i u njemu su nacionalno i religijsko srasli kao što su srasli u svesti starog jevrejskog naroda. ${ }^{8}$ Rusi i Jevreji imaju najjače izraženu ideju mesijanstva te prenos duhovne vlasti u Moskvu implicira smenu bogoizabranog naroda kao bedema hrišćanstva. ${ }^{9}$ Posle nestanka Vizantije, ruski car je bio jedini pravoslavac na carskom tronu. Berđajev smatra da je duhovni krah ideje o Moskvi kao Trećem Rimu došao usled uprošćenog shvatanja da je Treći Rim izraz carske moći, snage države, čime je sveden na Moskovsko carstvo, kasnije na rusku imperiju, a u XX stoleću na Treću internacionalu. ${ }^{10}$ Car je postao namesnik Božji na zemlji koji istovremeno brine o interesima carstva i spa-

\footnotetext{
${ }^{3}$ Shamir, I. 2018. The US-Engineered Split With Constantinople Could Be the Best Thing for the Russian Orthodox Church Ever.

https://russia-insider.com/en/us-engineered-split-constantinople-could-be-best-thing-russian-orthodox-churchever/ri25504

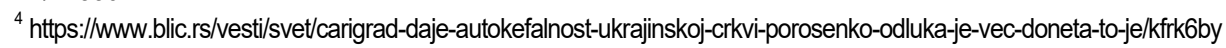

${ }^{5}$ Сафонов, П. 2019. Унижение томосом. Уникально ущербная украинская автокефалия. https://aurora.network/articles/10-vlast-i-obshhestvo/64485-unizhenie-tomosom-unikal-no-ushherbnaja-ukrainskaja-avtokefalija

${ }^{6}$ Mitropolit Nikolaj (Hadžinikolau) 2018. Podijeljene autokefalne Crkve ili ujedinjena braća?! http://www.hodocasca.rs/mitropolit-nikolaj-hadzinikolau-podijeljene-autokefalne-crkve-ili-ujedinjena-braca/

${ }^{7}$ Mitropolit Nikolaj (Hadžinikolau) 2018. Podijeljene autokefalne Crkve ili ujedinjena braća?!

${ }^{8}$ Berđajev, N. 1989. Izvori i smisao ruskog komunizma. Književne novine, Beograd, prevod i predgovor M. Đorđević, str. 3.

${ }^{9}$ Isto, str. 3.

${ }^{10}$ Berđajev, N. 2001. Ruska ideja. Osnovni problemi ruske filosofske misli XX i XX veka. Brimo. Beograd. Prevod: M. Marković, B. Marković, str. 12.
} 
senju duša. ${ }^{11}$ Ideja Trećeg Rima doprinela je jačanju i učvršćivanju Moskovske države, samodržavlja a ne procvatu duhovnog života te je hrišćanska misija ruskog naroda izneverena. $^{12}$

U Rusa se sukobljavaju dva elementa, prirodni paganizam, beskrajna stihija ruske zemlje i pravoslavlje preuzeto od Vizantije, asketizam, žudnja za drugim svetom. ${ }^{13} \mathrm{Ru}$ si su bili pred velikim zadatkom - da organizuju i uobliče beskrajnu zemlju čiji pejzaž odgovara pejzažu ruske duše. ${ }^{14}$ Osim što je savladavala velika prostranstva, Rusija je asimilovala zapadne ideje i predavala ih narodima koji su živeli u njoj a istovremeno se branila od vojničkih pohoda zavojevača. Suočena s brojnim geografskim, civilizacijskim i duhovnim izazovima, Moskovska Rusija svestrano se razvijala u različitim pravcima o čemu svedoče i visoki dometi njene likovne umetnosti i čitava kultura oblikovana neprekidnim suprotstavljanjem latinskom Zapadu i tuđinskim običajima. ${ }^{15}$ Nasuprot ruskom beskraju i stremljenju beskonačnosti, najdaljim delovima kosmosa i čoveka, stoji zapadnoevropski svet, omeđen, dovršen i sistematizovan kao u filosofskim sistemima Nemaca.

Desno-konzervativnom geopolitičkom projektu Trećeg Rima danas su u Rusiji privrženi RPC, monarhisti, deo poslovnih i političkih krugova ali i monaštvo i sveštenstvo pravoslavnih crkava južnoslovenskih naroda, te malobrojni zapadni Sloveni.

\section{Kriza EU i raspad sanitarnog kordona}

Razvoj događaja u Evropi podstiče Kremlj da oživi stari projekat Trećeg Rima te se u Dumi iznova ocenjuje odluka o povlačenju ruske vojske iz istočne Evrope. ${ }^{16}$ Osim ekonomskih i tehnoloških interesa, rusku obnovu interesovanja za Evropu podstiče i tegoban izlazak V. Britanije iz EU, migrantska kriza (prebacivanje stanovništva Azije i Afrike u atlantski deo EU), kulturna, politička, etnička razgradnja evropskih društava i kriza upravljanja.

Pre ili kasnije, moglo bi doći do razgraničenje zona odgovornosti u Evropi, između Rusije, SAD i Velike Britanije. U novonastalim okolnostima sanitarni kordon bi mogao biti podeljen u nekoliko prelaznih zona između Rusije i zapadne Evrope (Nemačke) i stavljen pod neposredni nadzor Kremlja. Sedište južne zone bio bi Beograd (pravoslavni južni Sloveni), centralnoevropske Budimpešta (katolici i protestanti). Baltičke republike, Belorusija i Ukrajina činile bi severnu zonu. Poljska bi mogla da ostane zasebna neutralna država (siva zona kao nekada SFRJ) ili da se priključi nekoj od susednih zona. Desetak

\footnotetext{
${ }^{11}$ Isto, str. 12.

12 Isto, str. 13.

${ }^{13}$ Berđajev, N. 1989. Izvori i smisao ruskog komunizma. Književne novine, Beograd, prevod i predgovor M. Đorđević, str. 2

${ }^{14}$ Isto, str. 2.

${ }^{15}$ Isto, str. 1.

${ }^{16}$ Predsednik komiteta za odbranu Dume Vladimir Šamanov predložio je da se da negativna ocena sporazuma sovjetskog rukovodstva o uništavanju raketa srednjeg i kratkog dometa i povlačenje sovjetske vojske iz istočne Nemačke u poslednjoj decenije XX stoleća. Moskva, 6.12. 2018. https://www.interfax.ru/russia/641035
} 
godina nakon uspostavljanja i stabilizacije prelaznih zona, moglo bi se pristupiti njihovom daljem uređenju. Neke od država iz prelaznog pojasa vremenom bi se ujedinile sa Rusijom (severna zona) dok bi druge ušle u sastav novog istočnog carstva i bile podvrgnute administrativnom preuređenju. Ovaj pravac promena u istočnoj Evropi neizbežno će dovesti do smene lokalnih vladajućih elita.

\section{Zamke i prepreke na putu do Trećeg Rima}

Uspostavljanje jednog vojnog, duhovnog i teritorijalnog oblika - Trećeg Rima sa sedištem u Moskvi, nailazi na snažan otpor Londona i Vašingtona. Ovaj jedinstveni civilizacijski oblik bio bi veliki izazov za Srbiju jer bi se ona našla u novoj istorijskoj situaciji. U formaciji znatno široj i većoj od bivše Jugoslavije koja se tri puta neslavno raspala. Dva puta kao zajednica više naroda (Kraljevina Jugoslavija i SFRJ) a treći put kao zajednica dve srpske države (SRJ). Ako bi se krenulo starim putem već posle dve decenije nova regionalna tvorevina na Balkanu postala bi ponovo tamnica naroda, kako su nekada Hrvati i jugoslovenski komunisti označavali Kraljevinu Jugoslaviju. Kremlj će nastojati da izbegne zamke boljševičkog projekta (SSSR i Treća internacionala) ili projekta Ruske imperije Romanova ugašenog Revolucijom 1917. U protivnom bi se za nekoliko decenija suočio sa procesima koje je već iskusio u doba hladnog rata. Sudbine srpskog kralja Aleksandra Karađorđevića i ruskog cara Nikolaja Romanova poučne su za kreatore novih integracija u ovom delu sveta.

Sovjetski rukovodioci su obrazujući Varšavski ugovor (reakcija na osnivanje Atlantskog saveza) prenebregli pitanje koje je Veliki inkvizitor davno postavio Hristu: zašto si došao da nam smetaš ${ }^{17}$ Isto to pitanje danas Evropa postavlja Kremlju. Da li rusko zauzimanje za Evropu ima smisla ako se kroz dve decenije Rusija nađe u položaju u kome je bila 1990? Zašto bi se Srbija zalagala za slovensku (balkansku) federaciju ako bi mogla da zapadne u položaj u kome je bila 1991? Nakon dva balkanska, dva svetska i jugoslovenskog rata 1991/99. u XX stoleću, Srbija nema razloga da troši snage na izgradnju i održavanje Jugoslavije u kojoj je navukla mržnju okolnih naroda i njihovu nezahvalnost.

Da bi obezbedila povoljan položaj u postatlantističkoj Evropi Srbija će započeti učvršćivanje veza sa srpskim zemalja. Srbija, RS, potom i Crna Gora, mogu postati jezgro balkanskog regiona i integracioni oblik koji bi isključio stvaranje Superjugoslavije, nove tvorevine anglosaksonskog kova.

\section{Zaključak - jedan od ishoda raspada sanitarnog kordona}

Odnosi Srba i Rusa, naroda koji nikada nisu ratovali, izazovni su kako za srpsku tako i za rusku elitu budući da je ona odbila povratak na sovjetski model i bipolarizam ali je još uvek podeljena po pitanju konvergencije s evropskim elitama. S druge strane u srpskoj

\footnotetext{
${ }^{17}$ Veliki Inkvizitor je poema Ivana Karamazova, junaka romana Dostojevskog „Braća Karamazovi“. Radnja poeme odvija se u Sevilji (Španija) u XVI Stoleću i opisuje Hrista koji stvara čudo - vaskrsava iz mrtvih ali biva uhvaćen i zatvoren. Veliki Inkvizitor utamničenom Hristu dokazuje da je Njegov novi dolazak na zemlju suvišan, ismejava čoveka i njegovu slabost, i otkriva Hristu da je bezbožnik.
} 
intelektualnoj eliti, koja često i sama učestvuje u vlasti, prevladavaju predstavnici hladnoratovskog i bretonvudskog poretka u nestajanju. To pokazuje i predsednik SANU koji zagovara da Srbija napusti (preda) Kosovo. ${ }^{18}$ Takav odnos snaga u intelektualnoj eliti uspostavljen je nakon pada komunizma jer od tada u Srbiji nije nastala i razvila se ni jedna uticajna grupa izvan evroatlantskog diskursa.

Uspostavljanje prelaznih zona između Rusije i zapadne Evrope, neposredno bi uticalo na rešavanje niza pitanja u antiruskom sanitarnom kordonu, uključujući hrvatsko i albansko. Istorijski gledano, nastanak Albanije i Hrvatske kao državnih oblika koji periodično izazivaju nestabilnost Balkana, zasluga je Beča, Berlina, Rima, ponajviše Londona. Smela najava albanskih vlasti da će samovoljno, posle ukidanja srpsko-albanske, otvoriti i granice prema BJRM, Grčkoj i Crnoj Gori i tako proširiti Albaniju, ukazuje na buduće diplomatske i vojne koalicije na Balkanu. ${ }^{19}$ Promene granica na Balkanu izvedene u poslednjoj deceniji XX stoleća, vode raspadu Srbije, Crne Gore, BJRM a možda i Grčke. Stoga, albansko pitanje zahteva drugačiji pristup od onog koji su praktikovale evropske sile u XX stoleću. Na prostoru prelaznih zona između Rusije i zapadne Evrope, neodrživo je rešenje koje bi se zasnivalo na podeli teritorije Srbije, tako što bi se na njenu štetu proširivale susedne države. Albansko i hrvatsko pitanje mogu se rešavati tek pošto se postigne dogovor o budućem uređenju istočne Evrope. ${ }^{20}$

O istrajnosti iznenada oživljenog geopolitičkog projekta Moskva - Treći Rim govore prozorljive reči monaha Filoteja upućene Ivanu III: „Trećega novog Rima, u državi moćnoga ti carstva, sveta saborna apostolska crkva pod vascelim nebom sjajnija od Sunca blista. I neka je znano državi tvojoj, blagočestivi care, da su se sva carstva pravoslavne vere hrišćanske u tvojoj državi stekla jer ti si, pod nebesima, jedini hrišćanski car. Pazi i bdij, blagočestivi care, jer su se sva hrišćanska carstva stopila u tvoje carstvo i znaj da su dva Rima pala, i da treći stoji, a da četvrtoga neće ni biti, hrišćansko carstvo tvoje više neće drugim dopasti..."21

Privodeći kraju ovu kratku raspravu ostajemo u nedoumici: ima li današnja Evropa snage da ponovi veliko delo Oktavijana Avgusta, osnivača Rimskog carstva? Ako li je nema zapadnoevropski svet, možda Rusija može da izvrši najveći i najteži zadatak u istoriji Evrope i uspostavi novo univerzalno carstvo na duhovnim temeljima. Ili su evropski i slovenski svet, ne snađu li se, osuđeni da siđu sa istorijske pozornice i utonu u tamu budućih stoleća? Prethodni milenijumi daju nadu da je put izbavljenja evropskog hrišćanskog sveta na dohvat ruke.

\footnotetext{
${ }^{18}$ Kostić: Kako sa elementima dostojanstva napustiti Kosovo? N1 http://rs.n1info.com/a101310/Vesti/Kostic-Kako-sa-elementima-dostojanstva-napustiti-Kosovo.html

${ }^{19}$ Albanski premijer Edi Rama u svojoj novogodišnjoj poruci kazao je da otvaranje granice s Kosovom tek početak i da albanska vlada planira da ukine i granicu prema Crnoj Gori, BJRM, Grčkoj. Večernje novosti 1.1.2019. http://www.novosti.rs/vesti/naslovna/politika/aktuelno.289.html:769246-Rama-Kosovo-je-samo-pocetakukinucemo-granice-i-prema-Makedoniji-Grckoj-i-Crnoj-Gori

${ }^{20}$ Lekić, S. 2018. Srbija, promene i balkanska mitologija. http://standard.rs/2018/08/24/srbija-promene-ibalkanska-mitologija/

${ }^{21}$ Berđajev, N. 1989. Izvori i smisao ruskog komunizma. Književne novine, Beograd, prevod i predgovor M. Đorđević, str. 3.
} 


\section{Literatura}

[1] Berđajev, N. 1989. Izvori i smisao ruskog komunizma. Književne novine, Beograd, prevod i predgovor M. Đorđević.

[2] Berđajev, N. 2001. Ruska ideja. Osnovni problemi ruske filosofske misli XX i XX veka. Brimo, Beograd, prevod: M. Marković, B. Marković.

[3] Kennan, G. 1946. George Kennan to George Marshall [“Long Telegram”], February 22, 1946. Harry S. Truman Administration File

https://www.trumanlibrary.org/whistlestop/study_collections/coldwar/documents/pdf/6-6.pdf

[4] Lekić, S. 2018. Srbija, promene i balkanska mitologija. http://standard.rs/2018/08/24/srbijapromene-i-balkanska-mitologija/

[5] Shamir, I. 2018. The US-Engineered Split With Constantinople Could Be the Best Thing for the Russian Orthodox Church Ever. https://russia-insider.com/en/us-engineered-splitconstantinople-could-be-best-thing-russian-orthodox-church-ever/ri25504

[6] Сафонов, П. 2019. Унижение томосом. Уникально ущербная украинская автокефалия. https://aurora.network/articles/10-vlast-i-obshhestvo/64485-unizhenie-tomosom-unikal-noushherbnaja-ukrainskaja-avtokefalija

[7] Hadžinikolau, N. (Mitropolit) 2018. Podijeljene autokefalne Crkve ili ujedinjena braća?! http://www.hodocasca.rs/mitropolit-nikolaj-hadzinikolau-podijeljene-autokefalne-crkve-ili-ujedinjena-braca/

[8] http://rs.n1info.com/a101310/Nest//Kostic-Kako-sa-elementima-dostojanstva-napustiti-Kosovo.html

[9] http://www.novosti.rs/vesti/naslovna/politika/aktuelno.289.html:769246-Rama-Kosovo-je-samopocetak-ukinucemo-granice-i-prema-Makedoniji-Grckoj-i-Crnoj-Gori

[10] https://rs.sputniknews.com/rusija/201803011114740983-Rusija-Vladimir-Putin-obracanjeskupstina-I

[11] https://rs.sputniknews.com/rusija/201803011114740983-Rusija-Vladimir-Putin-obracanjeskupstina-l

[12] https://www.blic.rs/vesti/svet/carigrad-daje-autokefalnost-ukrajinskoj-crkvi-porosenko-odluka-je-vecdoneta-to-je/kfrk6by

[13] https://www.interfax.ru/russia/641035 